\title{
Noggin is associated with a poor prognosis of gastric cancer by promoting the proliferation of gastric cancer cells via the upregulation of EGFR
}

\author{
ZHIWEI SUN ${ }^{1,2}$, XIANGYU GAO ${ }^{1,3}$, CATHERINE ZABKIEWICZ ${ }^{1}$, FIONA RUGE ${ }^{1}$, MENG XIE $^{1,3}$, SHUO CAI $^{1}$, \\ PING-HUI SUN ${ }^{1}$, PAUL GRIFFITHS ${ }^{4}$, MATTHEW R. PUGH ${ }^{4}$, JIAFU JI ${ }^{3}$, WEN G. JIANG ${ }^{1}$ and LIN YE ${ }^{1}$ \\ ${ }^{1}$ Cardiff China Medical Research Collaborative, Division of Cancer and Genetics, Cardiff University School of Medicine, \\ Cardiff CF14 4XN, UK; ${ }^{2}$ VIP-II Division of Medical Department, Key Laboratory of Carcinogenesis and Translational \\ Research (Ministry of Education, Beijing), Peking University Cancer Hospital and Institute; ${ }^{3}$ Key Laboratory of \\ Carcinogenesis and Translational Research (Ministry of Education), Gastrointestinal Tumour Center, \\ Peking University Cancer Hospital and Institute, Beijing 100142, P.R. China; ${ }^{4}$ Department of \\ Histopathology, Morriston Hospital, Heol Maes Eglwys, Swansea SA6 6NL, UK
}

Received January 21, 2020; Accepted May 12, 2020

DOI: 10.3892/ijo.2020.5081

\begin{abstract}
Noggin is an antagonist of bone morphogenetic proteins (BMP), being indispensable for certain developmental events. The present study aimed to examine the role of Noggin in the development and prognosis of gastric cancer (GC) and to elucidate the underlying mechanisms. The expression of Noggin in GC was evaluated by RT-qPCR, immunohistochemistry and by the analyses of publicly available databases. The effects of Noggin on proliferation, cell cycle, adhesion, invasion, colony formation and tumour spheroid were examined following both the knockdown and overexpression of Noggin in GC cell lines. The involvement of epidermal growth factor receptor (EGFR) signalling was examined by western blot analysis and by using small molecule inhibitors. As a result, a higher expression of Noggin in GC was found to be associated with a poorer overall survival. Noggin overexpression promoted the proliferation and
\end{abstract}

Correspondence to: Dr Lin Ye, Cardiff China Medical Research Collaborative, Division of Cancer and Genetics, Cardiff University School of Medicine, Cardiff CF14 4XN, UK

E-mail: yel@cardiff.ac.uk

Abbreviations: GC, gastric cancer; BMP, bone morphogenetic protein; TGF- $\beta$, transforming growth factor $\beta$; EMT, epithelial-mesenchymal transition; EGFR, epidermal growth factor receptor; PCR, polymerase chain reaction; IHC, immunohistochemistry; TCGA, The Cancer Genome Atlas; ERK, extracellular signal-regulated kinases; RANK, receptor activator of nuclear factor $\chi \mathrm{B}$; RANKL, receptor activator of nuclear factor $\chi \mathrm{B}$ ligand; DMEM, Dulbecco's modified Eagle's medium; FBS, foetal bovine serum; ATCC, American Type Culture Collection; RTK, receptor tyrosine kinases; MAPK, mitogen-activated protein kinase; PI3K, phosphoinositide 3-kinase

Key words: Noggin, bone morphogenetic protein, epidermal growth factor receptor, proliferation, gastric cancer colony formation of GC cells by promoting cell cycle progression. The knockdown of Noggin in HGC27 cells exerted an opposite effect on proliferation, colony formation and cell cycle progression. Noggin expression positively correlated with EGFR expression in both GC cell line models and The Cancer Genome Atlas human GC cohort. Targeting EGFR and its downstream pathways diminished cell proliferation which was promoted by Noggin. Furthermore, Noggin overexpression resulted in an enhanced nuclear translocation of $\beta$-catenin, leading to an upregulation of EGFR. Thus, the findings of the present study demonstrate that Noggin promotes the proliferation of GC cells by upregulating EGFR and enhancing a vicious circle formed by $\beta$-catenin, EGFR, ERK and Akt.

\section{Introduction}

Bone morphogenetic proteins (BMPs) are members of the transforming growth factor $\beta$ (TGF- $\beta$ ) superfamily. BMPs play a crucial role in the development of diverse tissues and organs, such as bone, cartilage, heart and other organs. Previous studies have demonstrated that BMPs play an important role in the regulation of the homeostasis of the gastric epithelium and tumourigenesis (1). As is known, the oxyntic mucosa is a complex structure that contains several types of cells, such as mucous pit, mucous neck, parietal, zymogenic and endocrine cells. BMP-4 has been implicated in the stimulation of $\mathrm{H}^{+} / \mathrm{K}^{+}$-ATPase $\alpha$-subunit gene expression and in the promotion of secretagogue-stimulated gastric acid production in canine parietal cells. These parietal cells may also regulate the process of differentiation and development of other cell lineages in the gastric mucosa by the production of regulatory factors and morphogens (2). The loss of mature parietal cells leads to a block in the differentiation program of zymogenic lineages and to the development of different types of mucosal cell remodelling. It has therefore been suggested that BMP signalling can regulate the homeostasis of the gastric epithelium through its ability to control the biological functions of parietal cells (1). 
The inhibition of BMP signalling in the gastric mucosa causes severe abnormalities in the proliferation, maturation and differentiation of several lineages of gastric epithelial cells, forming metaplasia, atypical hyperplasia and even tumours $(1,3)$. It has been observed that BMP-2 inhibits the growth of gastric cancer (GC) cells and that the epigenetic silencing of the BMP-2 gene through methylation can be detected in GCs (4). Others have also detected a decreased expression of BMP signalling molecules in GC (5), which reflects the inhibitory effect of BMPs on GC proliferation. In addition, BMPs have been associated with the metastasis of GC. The expression of BMP-4 has been found to be significantly higher in gastric adenocarcinoma compared to normal mucosa, and BMP-4 expression has been shown to be inversely associated with the prevalence of lymph node metastasis and tumour invasiveness (6). BMP-2 staining has been observed more frequently in intestinal-type GCs than in diffuse-type, and the expression of BMP-2 has been shown to be associated with pathological differentiation and lymph node metastasis. In vitro experiments have demonstrated that BMP-2 promotes the metastatic potential of GC cells through the phosphoinositide 3-kinase (PI3K)/Akt and mitogen-activated protein kinase (MAPK) signalling pathways, leading to the activation of nuclear factor (NF)- $x \mathrm{~B}$ and matrix metalloproteinase (MMP)-9 (7).

As a direct antagonist of BMP-2, BMP-4 and BMP-7, Noggin can bind to BMPs with high affinity, preventing their interaction with BMP receptors and consequently blocking downstream signal transduction. Noggin plays a role in both normal development and cancer. An elevated Noggin expression impairs BMP function, contributing to the osteolytic bone lesions in breast cancer (8). On the other hand, Noggin can potentially be utilised synergistically with receptor activator of nuclear factor $x \mathrm{~B}$ (RANK)/RANK ligand (RANKL)-targeted therapy for the treatment of the osteoblastic bone metastases of prostate cancer, by reducing BMP-induced osteoblastic activities (9). Laurila et al examined the expression of Noggin in tumour tissues $(n=208)$ of 34 different tumour types by immunohistochemistry (IHC). Among these samples, 8 cases were GC specimens. The results revealed that the expression levels were weak in 5 cases and 3 cases were moderate, while Noggin was expressed at a moderate level in normal gastric tissues (10). This indicates that Noggin may be differentially expressed in GCs compared with normal gastric tissues; however, this requires confirmation using a larger number of GC tissues.

The role of BMPs/Noggin in the development of tumours has received increasing attention in recent years and there are some indications that it plays an important role in GC; however, to date, knowledge of the involvement of BMPs/Noggin in GC remains poor. The present study aimed to examine the expression of Noggin in GC and its involvement in tumourigenesis and disease progression. In the present study, Noggin transcript levels were determined in a large cohort of $321 \mathrm{GC}$ tissues with 183 paired adjacent normal gastric tissues. Together with the analyses of Noggin expression in The Cancer Genome Atlas (TCGA) GC cohort and a cohort of GC data from KMplot, a significant association with patient overall survival was observed. Finally, in vitro experiments exploring the underlying mechanisms of this association revealed that Noggin promoted the proliferation of GC cells via the upregulation of epidermal growth factor receptor (EGFR).

\section{Materials and methods}

Public gene expression array data. KM plotter analysis (http://kmplot.com/) was performed to evaluate the expression of Noggin in GC tissues $(n=1,065)$ compared to normal gastric tissues $(n=57)$ and its association with the prognosis of patients following a previously reported procedure (11).

To identify the clinical significance of Noggin in GC, LinkedOmics was adopted, which is constructed based on TCGA with 415 cancer samples in the STAD dataset to explore the associations between Noggin expression and the patient clinicopathological parameters and overall survival (12).

GC samples. Gastric tumour tissues $(\mathrm{n}=321)$ and paired adjacent background tissues $(n=183)$ were collected immediately following surgery during the period between September, 2003 to December, 2007 and stored at $-80^{\circ} \mathrm{C}$ until use, with written consent from patients at the Peking University Cancer Hospital. RNA was isolated and converted into cDNA for subsequent quantitative PCR analysis. All protocol and procedures of the tissue collection were reviewed and approved by Peking University Cancer Hospital Research Ethics Committee.

IHC of gastric tissue microarray. Immunohistochemical staining was conducted on a gastric adenocarcinoma tissue microarray (OD-CT-DgStm01-007, FFPE, formaldehyde-fixed paraffin-embedded, US Biomax, Inc.) containing 108 cases of gastric adenocarcinoma, 10 cases of adjacent normal gastric tissue and 10 cases of chronic gastritis. In brief, anti-Noggin antibody (sc-16627, 1:50, $1 \mathrm{~h}$ at room temperature; Santa Cruz Biotechnology Inc.) and a biotinylated secondary antibody (1:50, $30 \mathrm{~min}$ at room temperature) was used (Vectastain Universal Elite ABC kit, PK-6200).

Cell lines and drug treatment. The GC cell lines, MKN7, NUGC4, MKN45, HGC27 and AGS, were purchased from the American Type Culture Collection (ATCC). Cells were routinely cultured at $37^{\circ} \mathrm{C}, 5 \%$ humidified $\mathrm{CO}_{2}$, in Dulbecco's modified Eagle medium (DMEM; MAC GENE) supplemented with 5\% foetal bovine serum (FBS; HyClone; GE Healthcare Life Sciences). Gefitinib (ZD1839, Selleckchem), $\beta$-catenin inhibitor (FH535, Apexbio), Akt inhibitor (MK-2206, Selleckchem) and ERK inhibitor (GDC-0994, Selleckchem) were employed to verify the involvement of the EGFR, ERK and Akt pathways.

RNA extraction and reverse transcription-PCR (RT-PCR). Total RNA was extracted from confluent cells in a $25 \mathrm{~cm}^{2}$ flask using the TRI Reagent kit (Sigma-Aldrich; Merck KGaA Inc.). Fresh-frozen tissues were also first homogenised in the TRI reagent followed by RNA extraction. The cDNA was then synthesised by RT reaction. The RT reaction was performed for $2 \mu \mathrm{g}$ total using the GoScriptTM Reverse Transcription System (Promega Corp.), followed by the amplification of Noggin (forward, 5'-TACAGATGTGGCTGTGGTCG-3' and reverse, 5'-TGCACTCGGAAATGATGGGG-3') by PCR. GAPDH (forward, 5'-GGCTGCTTTTAACTCTGGTA-3' and reverse, 5'-GACTGTGGTCATGAGTCCTT-3') was used as a control. PCR was carried out using the following 
conditions, $95^{\circ} \mathrm{C}$ for $5 \mathrm{~min}$, followed by $95^{\circ} \mathrm{C}$ for $30 \mathrm{sec}$ (30 cycles), $55^{\circ} \mathrm{C}$ for $30 \mathrm{sec}$, and $72^{\circ} \mathrm{C}$ for $30 \mathrm{sec}$ and a final extension of $5 \mathrm{~min}$ at $72^{\circ} \mathrm{C}$.

Quantitative PCR ( $q P C R)$. cDNA samples from GC tissues and cell lines were used for qPCR. qPCR for Noggin (forward, 5'-CAGCGCCTAAGCAAGAAG-3' and reverse, 5'-ACTGAAGCTGACCGTACAGTCGTTCCA CGCGTACAG-3') and GAPDH (forward, 5'- CTGAGTACG TCGTGGAGTC-3' and reverse, 5'- ACTGAACCTGACCGT ACACAGAGATGATGACCCTTTTG-3') was performed using the AmpliflourTM UniprimerTM system (InterGen) under the following conditions: $94^{\circ} \mathrm{C}$ for $10 \mathrm{~min}, 90$ cycles of $94^{\circ} \mathrm{C}$ for $10 \mathrm{sec}, 55^{\circ} \mathrm{C}$ for $35 \mathrm{sec}$, and $72^{\circ} \mathrm{C}$ for $20 \mathrm{sec}$. qPCR for p27 (forward, 5'-CGCCATATTGGGCCACTAA-3' and reverse, 5'-CGCAGAGCCGTGAGCAA-3'), cyclin D1 (forward, 5'- GCTCCTGGTGAACAAGCTCAA-3' and reverse, 5'-TTGGAGAGGAAGTGTTCAATGAAA-3') and GAPDH (forward, 5'- TGCACCACCAACTGCTTAGC-3' and reverse, 5'-GGCATGGACTGTGGTCATGAG-3') was performed using Power SYBR-Green PCR Master Mix (Applied Biosystems) under the following conditions: $94^{\circ} \mathrm{C}$ for $2 \mathrm{~min}$ and then 40 cycles of $94^{\circ} \mathrm{C}$ for $15 \mathrm{sec}$ and $55^{\circ} \mathrm{C}$ for $1 \mathrm{~min}$. the $2^{-\Delta \Delta \mathrm{Cq}}(13)$ method was be used for the analysis of the qPCR data.

Western blot analysis. The proteins were extracted using lysis buffer and the protein concentration of the cell lysates was determined using a DC protein assay kit (Bio-Rad Laboratories, Inc.). Protein (20 $\mu \mathrm{g}$ unless specifically stated) samples were separated on a SDS-PAGE gel (10\%) and then transferred onto PVDF membranes. The blotted membranes were incubated at $4^{\circ} \mathrm{C}$ overnight with primary antibodies (Table SI) and then with corresponding peroxidise-conjugated secondary antibodies (1:4,000; Sigma-Aldrich; Merck KGaA Inc. cat. no. A5278; A0545 and A5420) at room temperature for $1 \mathrm{~h}$. Nuclear proteins were prepared using nuclear isolation buffer (1.58 M sucrose, $40 \mathrm{mM}$ Tris- $\mathrm{HCl} \mathrm{pH}$ 7.5, $20 \mathrm{mM}$ $\mathrm{MgCl}_{2}, 4 \%$ Triton X-100). Protein bands were visualised using enhanced chemiluminescence (EZ-ECL) kit (Biological Industries, Israel Beit Haemek Ltd.).

Noggin knockdown and overexpression. Lentiviral Noggin shRNA and scramble control were purchased from Cyagen Biosciences, Inc. The shRNA sequence and negative control were as follows: Noggin sh9, GCTAGAGTTCTCCGAGGGCTT; scramble shRNA, CCTAAGGTTAAGTCGCCCTCG. Lentiviral particles were packaged using 293T cells (ATCC). A total of $2 \mu \mathrm{g}$ plasmids (including $1 \mu \mathrm{g}$ Noggin shRNA, $0.75 \mu \mathrm{g} \mathrm{pAX} 2$ and $0.25 \mu \mathrm{g}$ pMD2G) and UltraCruz Transfection Reagent (sc 395739; Santa Cruz Biotechnology Inc.) was used for transfection. The cells were incubated for $72 \mathrm{~h}$ and the lentivirus was collected. The full-length human Noggin coding sequence was amplified from a cDNA library derived from normal prostate tissue subject to cloning into a mammalian expression plasmid vector ( $\mathrm{pEF6/V5-His} \mathrm{TOPO} \mathrm{TA} \mathrm{plasmid} \mathrm{vector,}$ Invitrogen, Life Techologies; Thermo Fisher Scientific, Inc.). The lentiviral shRNA and Noggin expression plasmid vector were used to establish Noggin knockdown and overexpression cell lines for the subsequent experiments.
Cell proliferation assay. Cells were seeded into 96-well plates at 3,000 cells per well and incubated at $37^{\circ} \mathrm{C}$ with $5 \% \mathrm{CO}_{2}$ for a period up to $120 \mathrm{~h}$. Leica DM IRB microscope (Leica Microsystems $\mathrm{GmbH}$ ) was used to examine the cells. The cells were then fixed in $4 \%$ formaldehyde and stained with $0.1 \%$ crystal violet (Sigma-Aldrich; Merck KGaA Inc.). Absorbance of the staining was determined at a wave length of $540 \mathrm{~nm}$ using a spectrophotometer (Elx800, BioTek Instruments, Inc.) after the stained crystal violet was dissolved with $10 \%$ acetic acid. The GraphPad Prism v.6.0 (GraphPad Systems Inc.) program was utilized to analyse the data.

Clonogenic assay. A total of 300 cells are seeded in 6-well plates and incubated at $37^{\circ} \mathrm{C}, 5 \%$ humidified $\mathrm{CO}_{2}$ for 10 days. The cells were then fixed with $4 \%$ formalin and stained with $0.5 \%$ crystal violet at room temperature for $15 \mathrm{~min}$. The number of colonies was then counted using Leica DM IRB microscope (Leica Microsystems GmbH). The GraphPad Prism v.6.0 (GraphPad Systems Inc.) program was utilized to analyse the data.

Cell adhesion assay. Cell-matrix adhesion was conducted by seeding 30,000 cells per well onto a 96-well plate pre-coated with Matrigel (BD Biosciences). Non-adherent cells were washed off with PBS buffer following 40-min incubation at $37^{\circ} \mathrm{C}$, and the remaining adherent cells were fixed with $4 \%$ formalin, stained with $0.5 \%$ crystal violet (Sigma-Aldrich; Merck KGaA Inc.) at room temperature for $15 \mathrm{~min}$ and counted using a Leica DM IRB microscope (Leica Microsystems $\mathrm{GmbH}$ ). The GraphPad Prism v.6.0 (GradPad Systems Inc.) program was utilized to analyse the data.

Cell invasion assay. Transwell inserts (Greiner Bio-One Ltd.) with an $8.0 \mu \mathrm{m}$ pore size were coated with $50 \mu \mathrm{g}$ Matrigel and air-dried. Following rehydration in BSS buffer, 30,000 cells were seeded and incubated at $37^{\circ} \mathrm{C}$ for $72 \mathrm{~h}$. Cells that had invaded through the matrix and attached to the other side of the bottom membrane were fixed with $4 \%$ formalin and stained with $0.5 \%$ crystal violet at room temperature for $15 \mathrm{~min}$. The invaded cells were destained with acetic acid (10\%), and the absorbance of the staining was determined at a wave length of $540 \mathrm{~nm}$ using a spectrophotometer (Elx800, BIO-TEK, UK). The GraphPad Prism v.6.0 (GraphPad Systems Inc.) program was utilized to analyse the data.

Cell cycle analysis. Cells were cultured in serum-free medium for $36 \mathrm{~h}$ to synchronise the cell cycle, which was followed by a further $12-16 \mathrm{~h}$ of incubation at $37^{\circ} \mathrm{C}$ in medium with $10 \%$ FCS. Cells were harvested, fixed and stained with propidium iodide (PI) $(20 \mu \mathrm{g} / \mathrm{ml} \mathrm{PI}, 2 \mathrm{mg} / \mathrm{ml}$ RNase A, and $0.1 \%$ Triton X-100 in phosphate-buffered saline). DNA content was determined with FACSCantoTM II (BD Biosciences). The cell cycle was analysed using FCS Express (v4.0, De Novo Software).

Statistical analysis. Following a normality check, the t-test was employed for normally distributed data, whilst non-normally distributed data was analysed using the Mann-Whitney test. One-way ANOVA was used for comparisons of continuous data between multiple groups, and the Tukey's test was used 

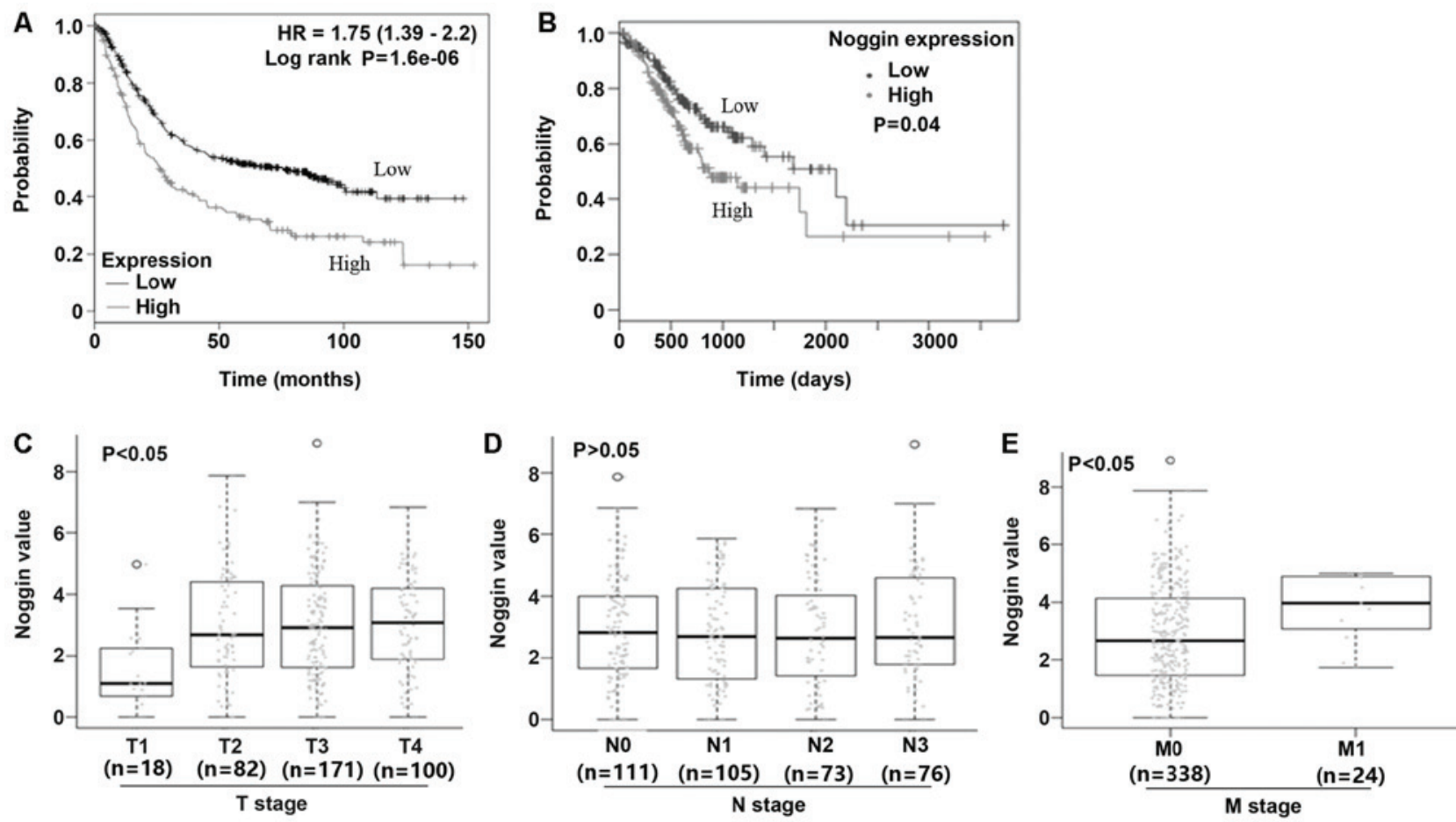

F a
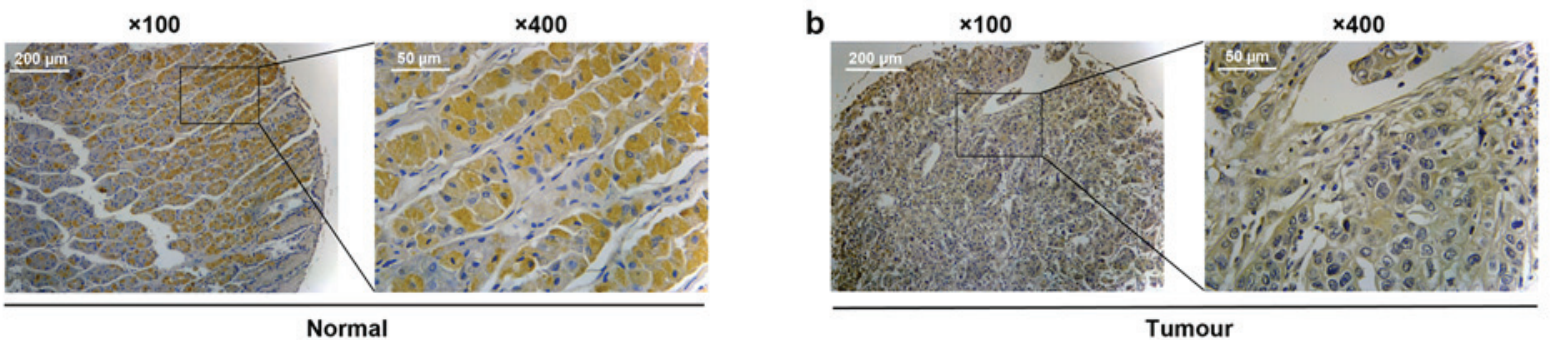

Figure 1. A higher Noggin expression is associated with a poorer overall survival of patients with GC. Kaplan-Meier survival analyses revealed associations between Noggin expression and the overall survival of patients with GC in both (A) the GC cohort; KMplot (cut-off value was 42) and (B) TCGA data (cut-off value was 2.72). Association between Noggin mRNA expression and (C) T stage ( $n=330)$, (D) N stage ( $n=329)$ and (E) M stage ( $n=318)$ of GC in the TCGA cohort. (F) Immunohistochemical analysis of Noggin expression in (a) normal tissues and (b) tumor tissues. GC, gastric cancer; TCGA, The Cancer Genome Atlas.

for further comparisons between groups following ANOVA. All experiments were repeated 3 times, and the results are expressed as the means $\pm \mathrm{SD}$. Differences were considered as statistically significant at $\mathrm{P}<0.05$. Data were analysed with SPSS software v20 (IBM Corp.). Pearson's correlation coefficient was applied to test the correlation between two variables. Survival analysis was performed using the Kaplan-Meier method, and the log-rank test was used to assess statistically significant differences.

\section{Results}

Higher expression of Noggin in GC is associated with disease progression and a poor prognosis. Kaplan-Meier survival analyses in both KMplot (Fig. 1A) and the TCGA database (Fig. 1B) revealed that patients with a higher expression of Noggin in their primary tumour exhibited a poorer overall survival than those with a low expression. In the KMplot GC cohort, patients with a higher expression exhibited a markedly shorter survival (median, 26.3 months) being approximately $1 / 3$ of that of patients with tumours expressing lower levels of Noggin (median, 75.5 months).
A higher expression of Noggin in the GC tumours was also associated with a shorter time to first progression (FP, median, 16.1 months, $\mathrm{P}<0.001)$ compared with a lower expression of Noggin (median, 49.5 months). The association between clinicopathological parameters of patients with GC and Noggin expression was further analysed using the TCGA database and it was found that the expression of Noggin was significantly associated with $\mathrm{T}$ stage $(\mathrm{P}<0.05)$ and with $\mathrm{M} 1$ (metastatic) disease $(\mathrm{P}<0.05$; Fig. $1 \mathrm{C}$ and $\mathrm{E})$. However, Noggin expression exhibited no significant association with $\mathrm{N}$ staging (Fig. 1D). In contrast to the finding of the association of a higher Noggin expression with disease progression and a poor prognosis, a decreased expression of Noggin in GC was observed in a collective gene expression array database of GC in which GC tumours $(n=1,065)$ exhibited lower Noggin expression levels compared with normal gastric tissues ( $\mathrm{n}=57$; KMplot) (data not shown). Immunochemical staining of Noggin in a gastric tissue array (Fig. 1F) and the quantification of Noggin transcripts in a cohort of GC by RT-qPCR (Table SII) also revealed a decreased expression of Noggin in GC compared with adjacent normal gastric tissues. 
A

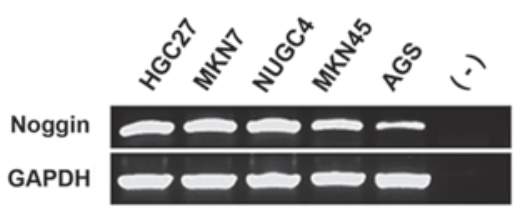

C

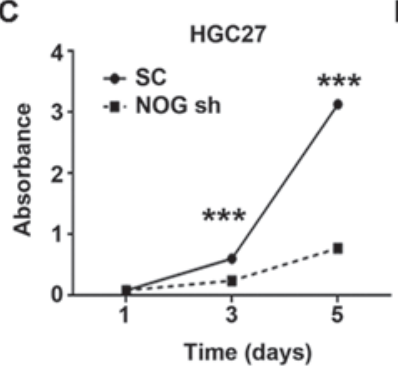

D

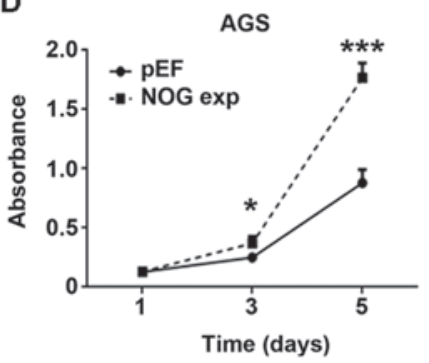

F

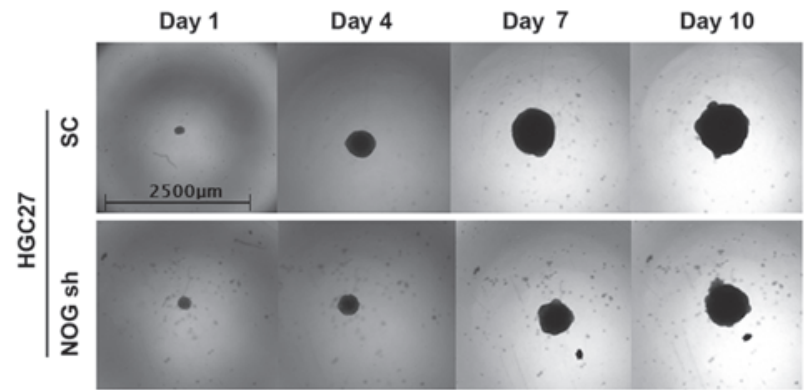

B

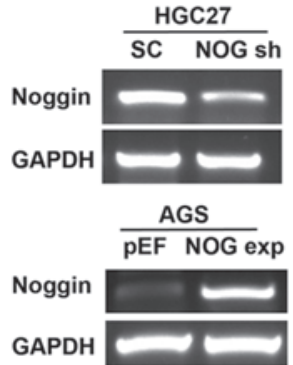

E
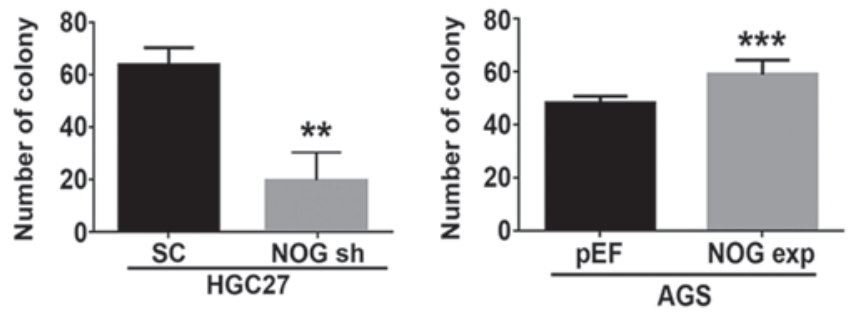

G

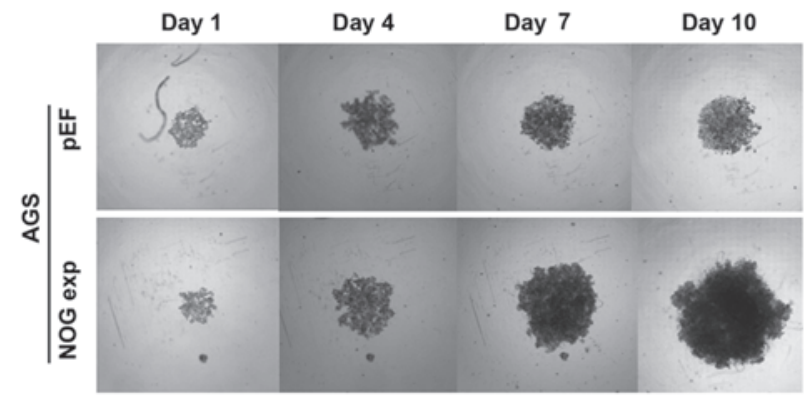

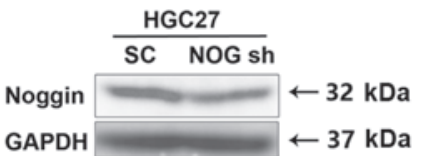

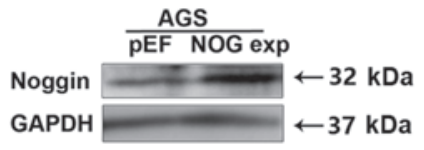

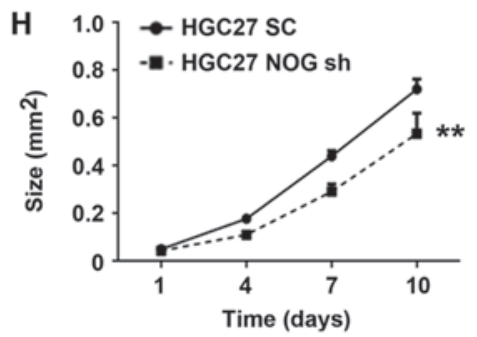
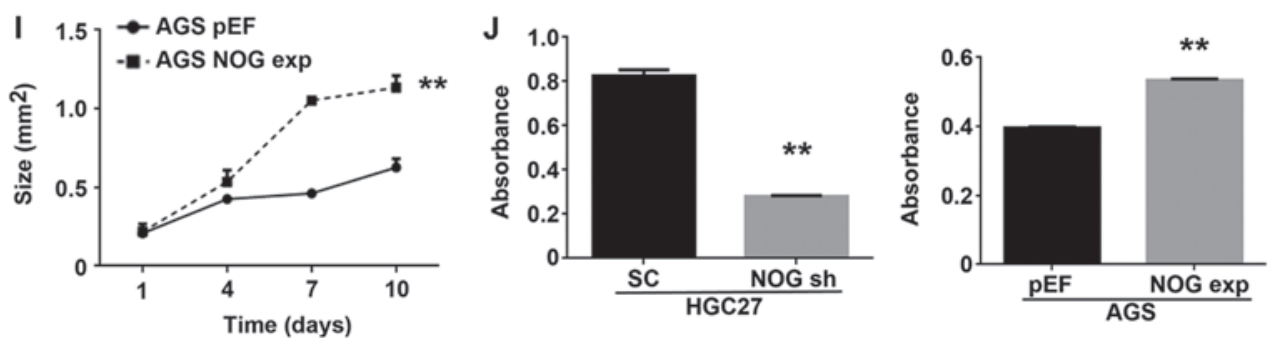

Figure 2. Noggin regulates the proliferation and invasion of GC cells. (A) Noggin expression in gastric cancer cell lines at mRNA levels using PCR. (B) Noggin knockdown and overexpression in HGC27 and AGS were confirmed by RT-qPCR and western blot analysis, respectively. Cell proliferation assay was performed on the (C) HGC27 $7^{\text {NOGsh }}$ cells and (D) AGS ${ }^{\text {NOGexp }}$ cells. (E) Colony formation assay was performed on the HGC27 $7^{\text {NOGsh }}$ and AGS ${ }^{\text {NOGexp }}$ cells. Growth of the (F and H) HGC27 $7^{\text {NOGsh }}$ and (G and I) AGS ${ }^{\text {NOGexp }}$ cells was examined using a 3D spheroid model. Size of 3-D acini of (H) HGC27 $7^{\text {NOGsh }}$ cells and (I) AGS ${ }^{\text {NOGexp }}$ cells was determined using ImageJ software. (J) Transwell invasion assay was performed to evaluate the effects of Noggin on the invasiveness of GC cell lines. A minimum of 3 independent experiments was performed. Shown are representative experimental data. ${ }^{*} \mathrm{P}<0.05,{ }^{* *} \mathrm{P}<0.01$ and ${ }^{* * *} \mathrm{P}<0.001$ compared to the respective control. GC, gastric cancer.

Noggin promotes proliferation and colony formation of GC cells. To explore the cellular machinery underlying the role of Noggin in disease progression, the expression of Noggin was examined in 5 GC cell lines, including HGC27, MKN7, NUGC4, MKN45 and AGS using conventional PCR. Noggin expression was detectable in all 5 cell lines, while the AGS cell line expressed a relatively lower level (Fig. 2A). The knockdown and overexpression of Noggin were subsequently established in the HGC27 and AGS cells using the lentiviral Noggin shRNA and Noggin overexpression plasmid vectors, respectively (Fig. 2B). Following the knockdown of Noggin, the HGC27 cells exhibited a decreased proliferation, while Noggin overexpression promoted the proliferation of the AGS cells (Fig. 2C and D). Colony formation assays revealed that Noggin overexpression promoted the proliferation of the AGS cells, while a marked decrease in colony numbers was observed in the HGC27 cells in which Noggin was knocked down (Fig. 2E). The effects of Noggin on the growth of GC cell lines were further evaluated using an in vitro 3D spheroid model (Fig. 2F and G). The knockdown of Noggin resulted in an inhibition of the growth of HGC27 cells (Fig. 2H), whereas Noggin overexpression significantly increased the growth of AGS cells (Fig. 2I). 

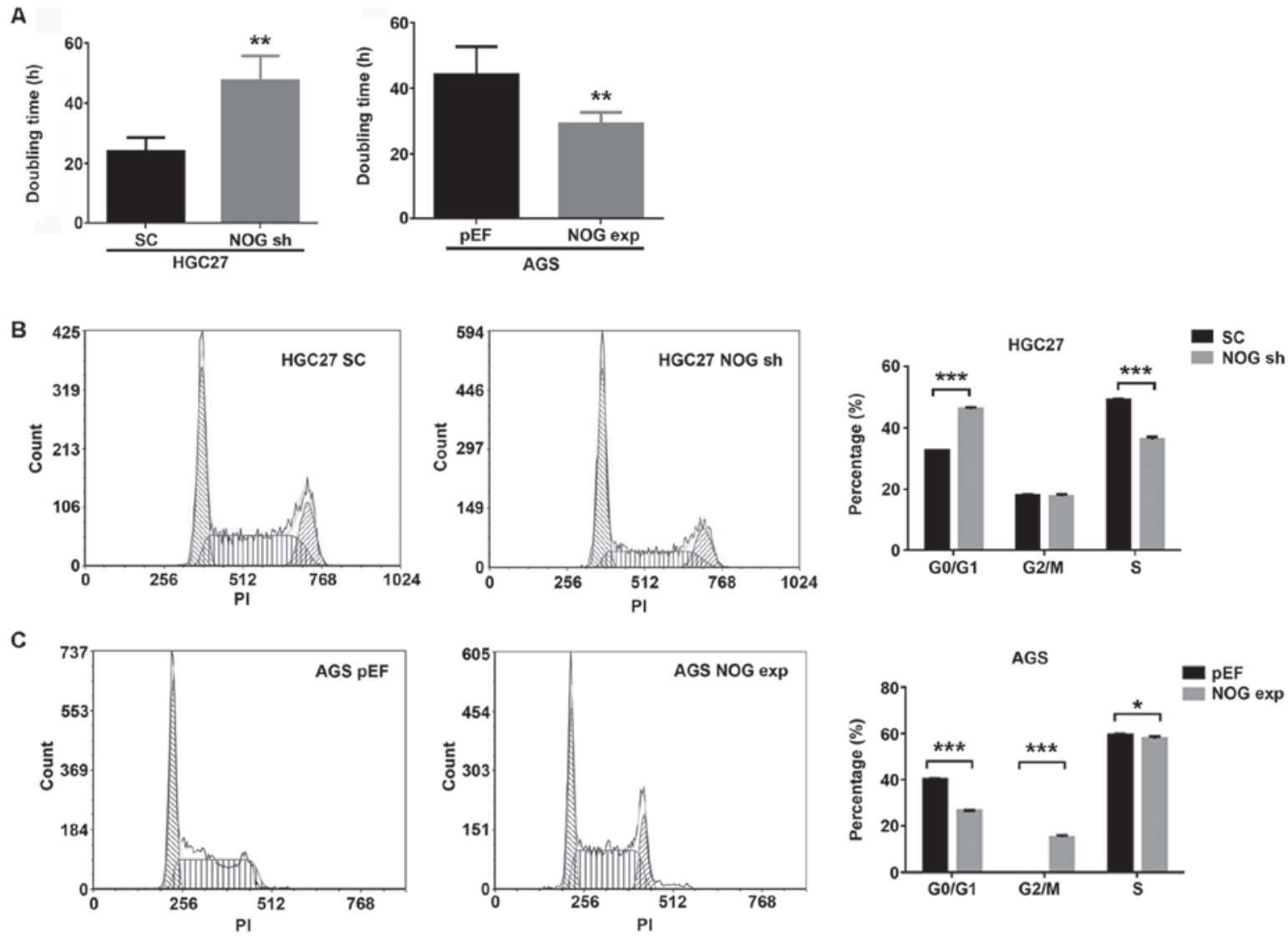

D
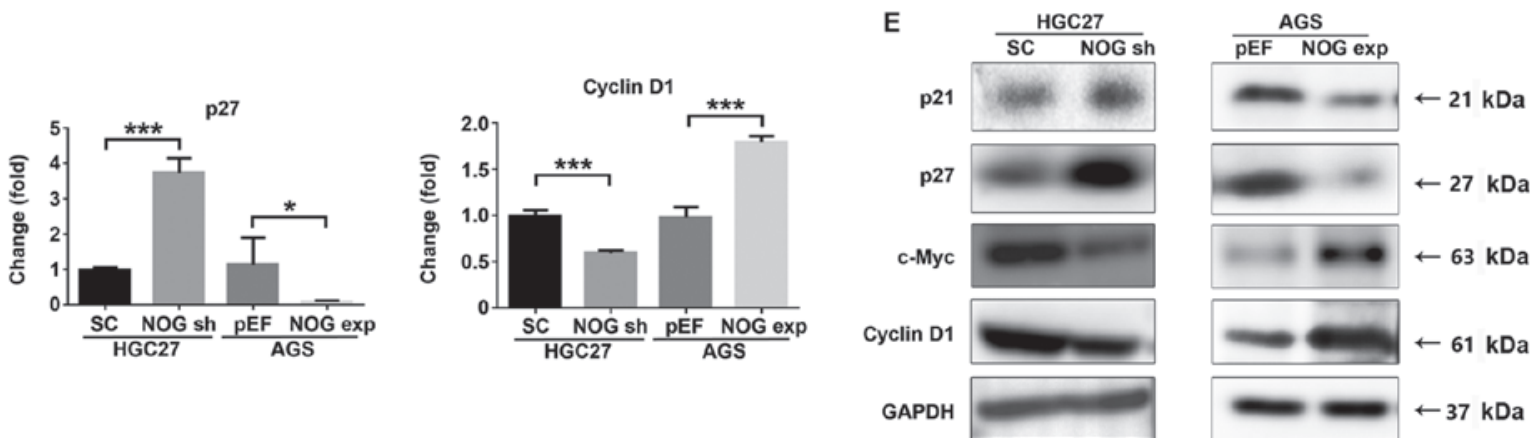

Figure 3. Noggin regulates the cell cycle of GC cells. (A) Doubling time of HGC27 $7^{\text {NOGsh }}$ and AGS ${ }^{\text {NOGexp }}$ cells was calculated based on the proliferation tests (B) Cell cycle analysis showing the automated calculation of different populations allocated at each phase of the cell cycle and the overall percentage of cells according to cell cycle phases in the HGC27 cell lines. (C) Effect of Noggin overexpression on the cell cycle of AGSpEF, AGS ${ }^{\text {NOGexp }}$ and percentage of cells according to cell cycle phases. (D) RT-qPCR was employed to determine the expression of p27 and cyclin D1 in both the HGC27 and AGS cell lines. (E) Protein expression of p21, p27, cMyc and cyclin D1 determined by western blot analysis. A minimum of 3 independent experiments was performed. Shown are representative experimental data. ${ }^{*} \mathrm{P}<0.05,{ }^{* *} \mathrm{P}<0.01$ and ${ }^{* * *} \mathrm{P}<0.001$ compared to the respective control. GC, gastric cancer.

Noggin promotes the cell cycle of GC cells through the regulation of cell cycle regulators. The significant effects of Noggin on the proliferation of GC cell lines inspired us to further explore the underlying cellular events and molecular mechanisms. To explore the molecular mechanisms underlying the proliferation-promoting effects of Noggin in GC, the doubling time of the HGC27 and AGS cell lines was first calculated. It took longer for the cells in which Noggin was knocked down to double once, in comparison with the control cells, whilst the cells in which Noggin was overexpressed doubled more rapidly, with the doubling time being approximately $30 \%$ shorter than that of the control cells (Fig. 3A). The cell cycle of the HGC27 and AGS cell lines was further analysed by a flow cytometric assay. As shown in Fig. 3B, there was a lower percentage cells in which Noggin was knocked down progressing to the $\mathrm{S}$ phase in the compared to the control, while a greater percentage of these cells remained at the $\mathrm{G} 0 / \mathrm{G} 1$ phase. Conversely, there was a higher percentage of Noggin-overexpressing cells entering the $\mathrm{G} 2 / \mathrm{M}$ phase and the G0/G1 population of these cells decreased compared with the control (Fig. 3C). In addition, the expression of cell cycle markers was examined in the AGS cells and HGC27 cells by RT-qPCR and western blot analysis (Fig. 3D and E). In the Noggin-overexpressing AGS cells, the expression levels of p21 and p27 were decreased, while those of cMyc and cyclin D1 were increased. In contrast to the changes observed in the Noggin-overexpressing AGS cells, the HGC27 cells in which Noggin was knocked down exhibited an increased expression of p21 and p27, and a decreased expression of cMyc and cyclin D1. 
A
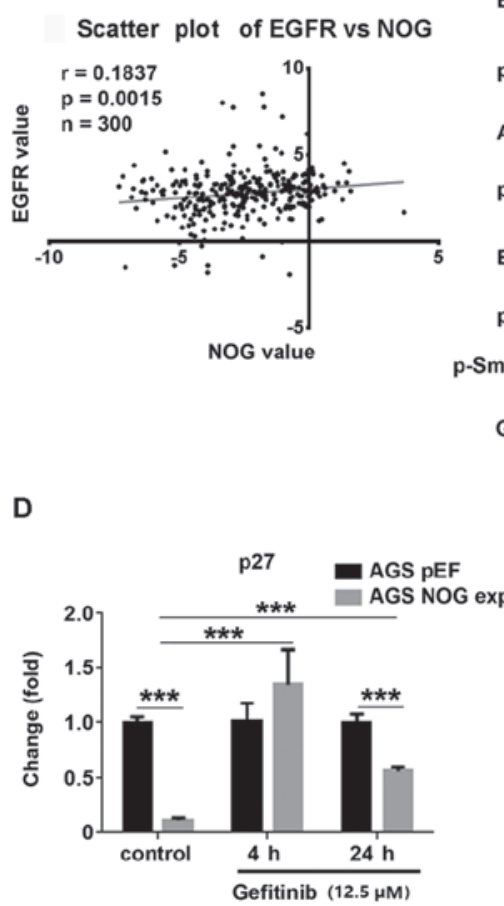

B

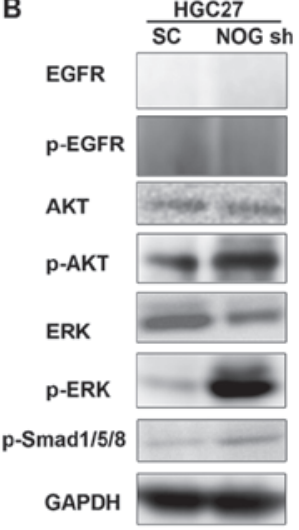

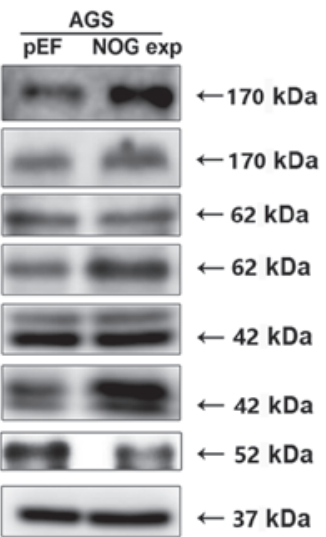

C

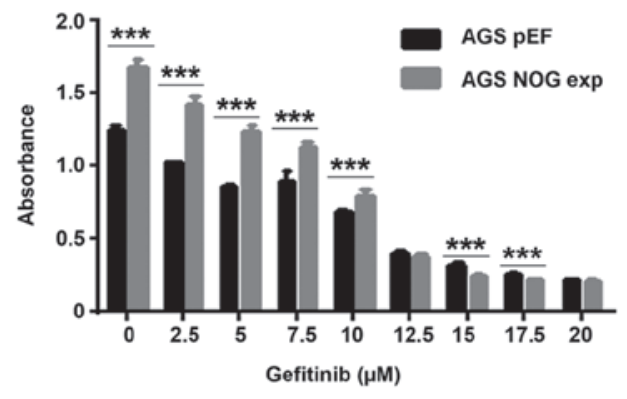

E

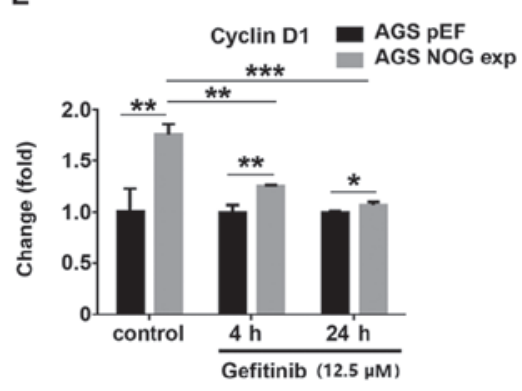

$\mathbf{F}$

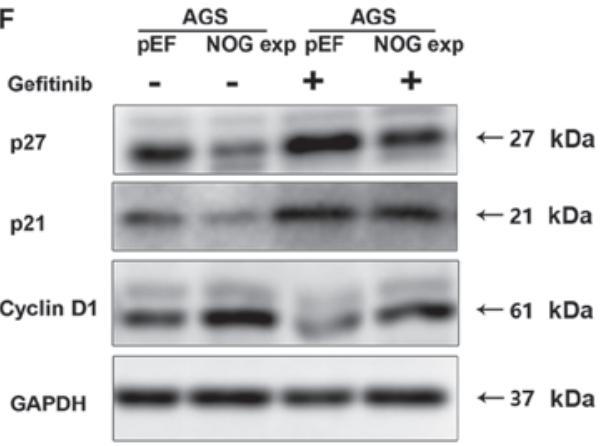

G

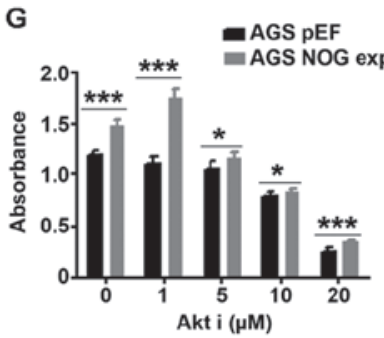

H

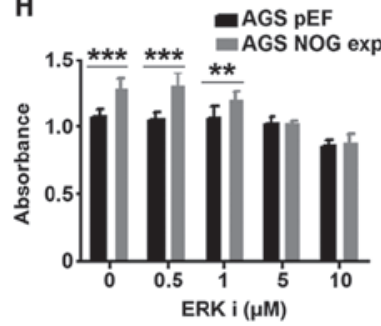

I

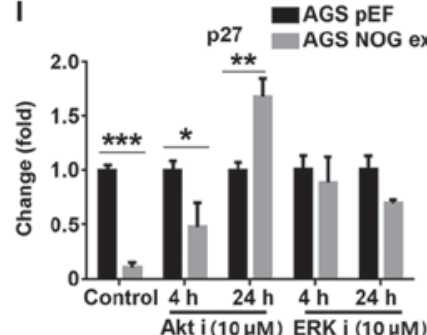

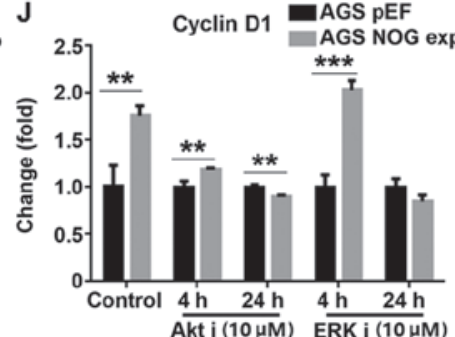

Figure 4. EGFR/ERK/Akt in Noggin regulates the proliferation of GC cell lines. (A) Correlation between Noggin and EGFR in the TCGA database. (B) Activation of EGFR, ERK and Akt in both HGC27 $7^{\text {NOGsh }}$ and AGS ${ }^{\text {NOGexp }}$ cell lines determined by western blot analysis. (C) Involvement of EGFR in the Noggin-promoted proliferation of AGS cells was examined using the EGFR inhibitor, gefitinib. RT-qPCR was performed to determine the involvement of EGFR in the Noggin-regulated expression of (D) p27 and (E) cyclin D1 following the application of gefitinib (12.5 $\mu$ mol/l). (F) Corresponding protein expression was determined by western blot analysis. Cell proliferation assays were performed on AGS ${ }^{\text {NOGexp }}$ cells treated with various concentrations of $(\mathrm{G})$ Akt inhibitor and (H) ERK inhibitor. Expression of (I) p27 and (J) cyclin D1 in AGS ${ }^{\text {NOGexp }}$ cells treated with either AKT inhibitor or ERK inhibitor determined by RT-qPCR. A minimum of 3 independent experiments was performed. Shown are representative experimental data. ${ }^{*} \mathrm{P}<0.05,{ }^{* *} \mathrm{P}<0.01$ and ${ }^{* * * *} \mathrm{P}<0.001 \mathrm{compared}$ to the respective control. GC, gastric cancer.

Noggin promotes the invasion of GC cells. The effects of Noggin on the invasion of GC cell lines were also assessed. As shown in Fig. 2J, there was a significantly lower number of invading cells in the $\mathrm{HGC} 27^{\text {NOGsh }}$ cells compared with the control, and there were much more cells observed on the bottom side of the invasion inserts in the AGS ${ }^{\text {NoGexp }}$ cells in comparison with the control. These findings suggest that Noggin promotes the invasion of GC cells.

Noggin overexpression promotes cell proliferation through an upregulation of EGFR. There is a close association between BMP and EGFR signalling, including their mutual regulation of signal transduction and expression of key molecules (14). EGFR belongs to the family of receptor tyrosine kinases (RTK) ErbB, and it is regarded as an oncogenic factor being overexpressed in many kinds of cancers, including non-small cell lung cancer (15), colorectal cancer (16), pancreatic cancer (17), oesophageal cancer (18) and GC as well (19). It has previously been found that the overexpression of EGFR increases the proliferation of tumour cells through the PI3K/Akt signalling pathway (20). In the present study, the correlation between the expression of Noggin and EGFR was first analysed in the TCGA GC cohort using gene expression array data. A positive correlation was observed between Noggin and EGFR expression (Pearson's correlation) (Fig. 4A). The expression of EGFR and its signalling via ERK and Akt were determined by western blot analysis. The upregulation of EGFR and the enhanced downstream signalling of both ERK and Akt were observed in the AGS ${ }^{\text {NOGexp }}$ cells (Fig. 4B). Conversely, EGFR expression and activation were almost undetectable in the $\mathrm{HGC} 27^{\text {NOGsh }}$ and $\mathrm{HGC} 27^{\text {SC }}$ cells. Higher levels of both phosphorylated ERK, Akt and Smad1/5/8 were observed 


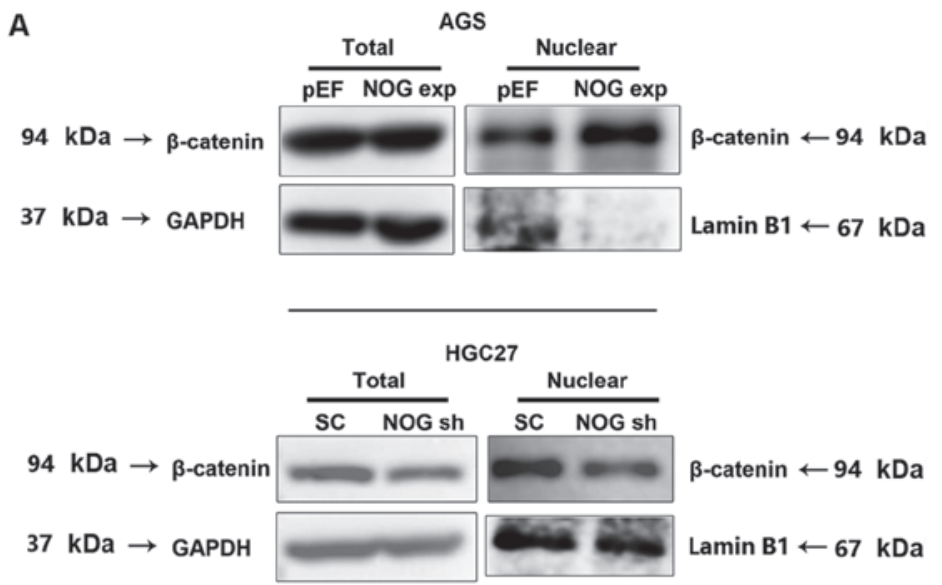

B

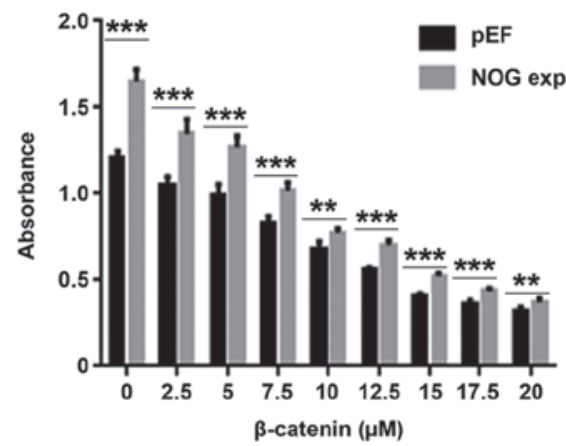

C
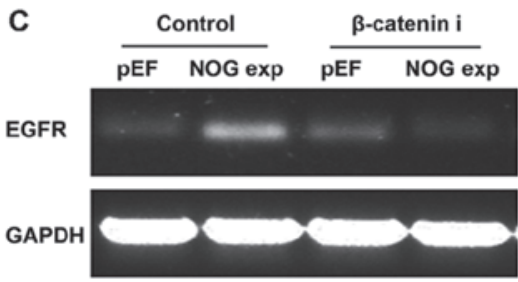

D
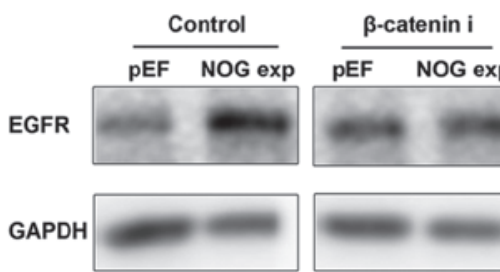

$\leftarrow 170 \mathrm{kDa}$
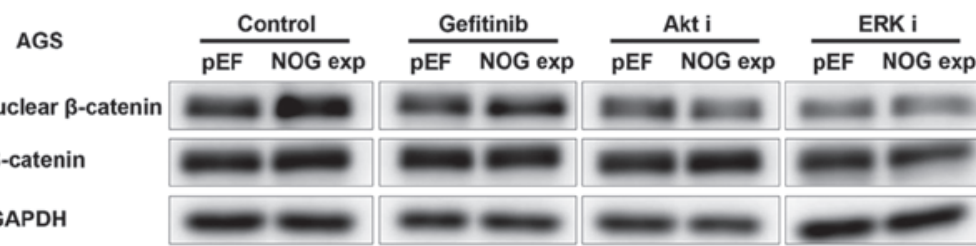

$\leftarrow 94 \mathrm{kDa}$

$\beta$-catenin

GAPDH

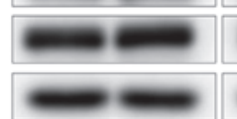

$\leftarrow 94 \mathrm{kDa}$ $\leftarrow 37 \mathrm{kDa}$

Figure 5. Noggin upregulates EGFR in GC cells through an enhanced vicious cycle formed by Akt, ERK, $\beta$-catenin and EGFR. (A) Western blot analysis was performed to examine $\beta$-catenin in both total cell lysates and nuclear protein of AGS and HGC27 compared with controls. (B) Cell proliferation assay was performed on AGS cells treated with various concentrations of $\beta$-catenin inhibitor. (C) RT-PCR and western blot analysis were performed to determine the expression of EGFR in AGS ${ }^{\text {NOGexp }}$ cells treated with $\beta$-catenin inhibitor in comparison with the vehicle control. (D) Nuclear translocation of $\beta$-catenin was

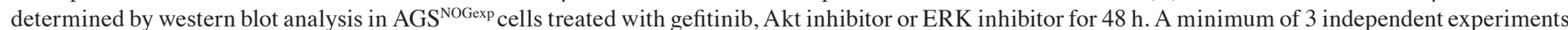
was performed. Shown are representative experimental data. ${ }^{* *} \mathrm{P}<0.01$ and ${ }^{* * *} \mathrm{P}<0.001$. GC, gastric cancer.

in the HGC27 $7^{\text {NOGsh }}$ cells compared to the control (Fig. 4B). The expression of EGFR was analysed at the mRNA level in different gastric cancer cell lines in the GSE36139 database, and it was found that the expression values of EGFR in the HGC27, MKN7, NUGC4, MKN45 and AGS cells were 5.39, 7.77, 6.64, 6.68 and 6.22, respectively. The HGC27 cells exhibited a lower expression of EGFR than the other 4 GC cell lines (data not shown). It was considered that this may be the reason for the failure to detect EGFR bands in the HGC27 cell line in the western blot analysis experiments in the present study.

To clarify the involvement of EGFR signalling in the Noggin-induced increase of the proliferation of AGS cells, the EGFR inhibitor, gefitinib, was employed. Treatment with gefitinib $(12.5 \mu \mathrm{M}, 72 \mathrm{~h})$ led to the concentration-dependent inhibition of the proliferation of AGS cells. The difference in the proliferation between the $\mathrm{AGS}^{\mathrm{NOGexp}}$ and $\mathrm{AGS}^{\mathrm{pEF}}$ group became less significant when the concentration of gefitinib was increased to a concentration $>12.5 \mu \mathrm{M}$ (Fig. 4C). Further RT-qPCR analysis revealed that the changes in both the expression of $\mathrm{p} 27$ and cyclin D1 in the AGS ${ }^{\text {NOGexp }}$ cells were abrogated with the addition of gefitinib (Fig. 4D and E). This was further supported by the determination of their protein expression by western blot analysis (Fig. 4F). Further experiments using small inhibitors targeting ERK and Akt revealed that both ERK and Akt were involved in the enhanced proliferation induced by Noggin-EGFR. Both ERK and Akt inhibitor were able eliminate the promoting effects of Noggin on the proliferation of the AGS cells (Fig. 4G and H). Similar to the addition of gefitinib, the effect on the cell cycle regulators, including p27 and cyclin D1 was also observed in the cells treated with both ERK and Akt inhibitor, respectively (Fig. 4I and J).

Noggin overexpression increases EGFR transcription by promoting the nuclear translocation of $\beta$-catenin. Previous studies have demonstrated that an interaction exists between the BMP signalling pathway and the $\mathrm{Wnt} / \beta$-catenin pathway $(21,22)$. The BMP signalling pathway can inhibit Wnt/ $\beta$-catenin signalling via the PTEN/PI3K/Akt pathway (21). In addition, EGFR is one of the target genes regulated by $\beta$-catenin. Therefore, the present study examined the protein level nuclear $\beta$-catenin in AGS cells by western blot analysis. An increase in the levels of nuclear $\beta$-catenin was observed in the AGS ${ }^{\text {NOGexp }}$ cells (Fig. 5A). No obvious change was noted for the expression of $\beta$-catenin in the total cell lysates. A corresponding reduced nuclear $\beta$-catenin was observed in the HGC $27^{\text {NOGsh }}$ cells. Subsequent proliferation assays with the 
A

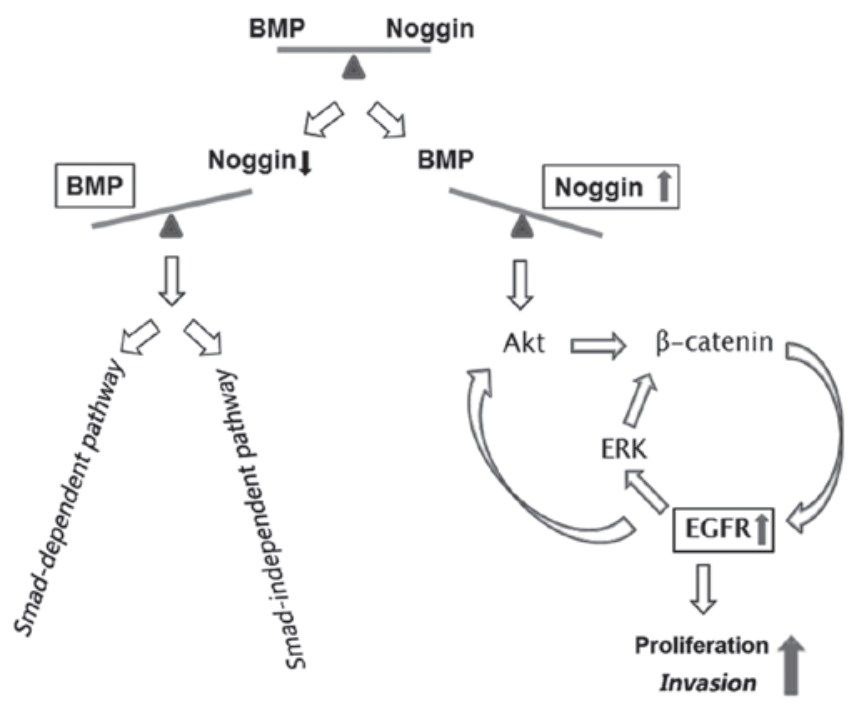

B
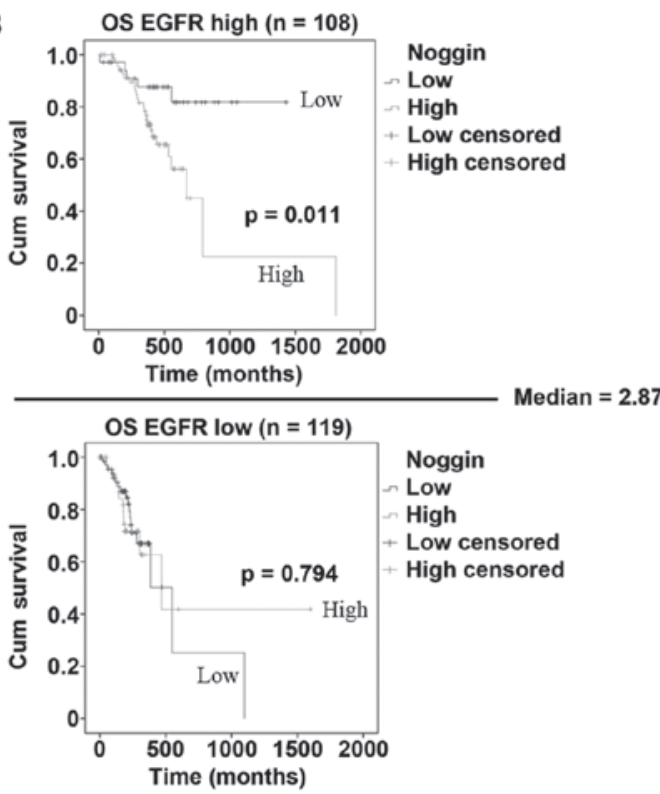

Figure 6. Noggin-induced vicious cycle and survival of patients with EGFR highly expressing tumours. (A) Enhanced vicious cycle involves Noggin upregulation of EGFR in GC cells. (B) Kaplan-Meier survival analyses demonstrated that high Noggin expression is associated with the poor overall survival of patients with high EGFR-expressing tumours. Cut-off values used in the survival analyses were as follows: Median of EGFR, 2.87 ; median of Noggin, -2.44. A minimum of 3 independent experiments was performed. Shown are representative experimental data. GC, gastric cancer.

addition of a $\beta$-catenin inhibitor revealed an inhibition of the proliferation promoted by Noggin overexpression in the AGS cells (Fig. 5B). The addition of $\beta$-catenin inhibitor also diminished the upregulation of EGFR in AGS ${ }^{\text {NOGexp }}$ cells which was evident at both the mRNA and protein level (Fig. 5C).

Of note, it was found that the EGFR, Akt and ERK inhibitors were able to prevent the Noggin-promoted nuclear translocation of $\beta$-catenin (Fig. 5D), which was in line with the findings of previous studies demonstrating that EGFR-mediated PI3K/Akt activation promotes $\beta$-catenin transactivation $(23,24)$. As shown in Fig. 6A, it is thus suggested that Noggin is able to enhance the vicious cycle formed by EGFR and Wnt/ $\beta$-catenin signalling, which reciprocally upregulate each other, ultimately leading to an unlimited/deregulated proliferation of GC cells. Further Kaplan-Meier survival analyses revealed that a high Noggin expression was significantly associated with a poorer overall survival of patients with EGFR high-expressing tumours (Fig. 6B).

\section{Discussion}

To date, knowledge of BMP signalling in GC is extremely limited. In the present study, we determined the expression of Noggin in human gastric tumour tissues together with paired adjacent normal tissues which showed reduced expression of Noggin in GCs. This is consistent with the analysis of Noggin expression in the TCGA GC cohort and also the IHC staining of Noggin in the gastric tissue microarray. Moreover, the present study analysed the Noggin promoter methylation status in 2 online databases (GSE30601 and TCGA GC) to explore the involvement of methylation in the decreased expression of Noggin in GC. It was demonstrated that there was an increased methylation of the Noggin promoter in gastric tumours compared with the paired adjacent normal stomach tissues (data not shown). Noggin expression was inversely associated with the methylation of Noggin promoter in the TCGA GC cohort (data not shown). The exact involvement of this methylation in the suppression of Noggin and the mechanisms through which it is implicated in tumourigenesis have yet to be elucidated. However, the analyses of Noggin expression in GC tumours according to their $\mathrm{T}$ staging revealed that the invasive, larger tumours exhibited a higher expression of Noggin compared with smaller tumours confined to the gastric mucosa. Advanced tumours with distant metastasis expressed higher levels of Noggin compared with localised disease. A significant association between a higher expression of Noggin and a shorter survival was evident in both the TCGA cohort and KMplot collection. Patients with a high Noggin expression in their tumours exhibited a markedly shorter survival, approximately $1 / 3$ of that of patients with tumours expressing lower levels of Noggin. This suggests that Noggin plays differential roles at different stages during tumourigenesis and the disease progression of GC, with the survival difference in high Noggin-expressing tumours of interest warranting further investigation.

Subsequent experiments revealed a dominating effect of Noggin on the cellular functions of GC cells with regard to the promotion of proliferation. This was evident in the proliferation assay, colony formation and 3D spheroid growth assay. Noggin expression was significantly associated with a shorter doubling time of GC cell lines, further supported by the findings in the cell cycle analyses which revealed the promoting effect of Noggin on cell cycle progression. Upon binding with BMP ligands, BMP receptors activate Smad1/5/8 to form a complex with Smad4 followed by nuclear translocation, thus regulating BMP responsive genes involved in cellular functions, including proliferation, differentiation, migration and invasion. BMP-induced Smad signalling can inhibit the cell cycle by increasing the transcription of p21 and p27 (25). 
Consistent with this, the overexpression of the BMP antagonist, Noggin, in the AGS cells, decreased p21 and p27 expression, whilst the level of cyclin D1 was increased. Opposite effects were observed in the HGC27 cells when Noggin was knocked down.

EGFR belongs to the family of receptor tyrosine kinases (RTK) ErbB, and it is overexpressed in numerous types of cancer, including non-small cell lung cancer, colorectal cancer, pancreatic cancer, oesophageal cancer and GC (15-19). EGFR overexpression has been described in $9-45 \%$ of GCs (26-28), while the EGFR gene is amplified in almost $2.3-16 \%$ of GCs $(26,28)$. In addition, EGFR mutations have been found in $4 \%$ of GCs (29). Increased EGFR signalling is associated with a higher stage, a poorly differentiated histology, increased invasiveness and a poor prognosis $(27,30,31)$. The known crosstalk between BMP and EGFR signalling prompted an exploration of the involvement of EGFR in Noggin-promoted proliferation and the link with the poorer survival of patients with GC. The initial analysis revealed a positive correlation of the expression of EGFR and Noggin in the TCGA GC cohort. A previous study identified that the overexpression of EGFR increases the proliferation of tumour cell through the PI3K/Akt signalling pathway (20). EGFR is recognized as an oncogenic driver in tumourigenesis and a target for cancer therapy. In the present study, further experiments revealed an increased expression of EGFR in the AGS cells following the overexpression of Noggin. The enhanced activation of corresponding downstream ERK and Akt pathways was also evident in the AGS ${ }^{\text {NOGexp }}$ cells. Experiments were then performed to verify the involvement of EGFR signalling in the Noggin-promoted proliferation of GC cells. The addition of gefitinib diminished the Noggin-promoted cell proliferation, which was accompanied by an increased expression of p21/p27 and a decreased expression of cyclin D1. Furthermore, Akt and ERK inhibitors were also able to prevent the Noggin-promoted cell proliferation with the corresponding changes in the cell cycle regulators. These results demonstrate that Noggin promotes the proliferation of GC cells through an upregulation of EGFR. The current finding in GC is also in line with the role played by Noggin in the regulation of gastric epithelial cells in a murine model. It was previously demonstrated that transgenic Noggin overexpression in a mouse model caused the activation of the proliferation of gastric epithelial cells through an upregulation of EGFR (32).

Taken together, Noggin can promote the proliferation of GC cells collectively through dual mechanisms; the Noggin-induced upregulation of EGFR leads to a promotion of proliferation, and in addition, the inhibition of proliferation by BMP signalling is antagonised by the increased level of Noggin.

It would be of interest to determine the mechanisms through which Noggin upregulates the expression level of EGFR. Although studies have confirmed the interaction between the EGFR pathway and the BMP pathway, the majority of studies have focused on the mechanisms through which the EGFR/Akt pathway regulates the BMP pathway $(33,34)$. To the best of our knowledge, only a few studies to date mention that the BMP pathway can also downregulate EGFR (35); however, the underlying molecular mechanisms remain unclear. Previous studies have demonstrated that there is an interaction between the BMP signalling pathway and the Wnt/ $\beta$-catenin pathway $(21,36)$. The BMP signalling pathway can inhibit Wnt/ $\beta$-catenin signalling via the PTEN/PI3K/Akt pathway (21). In addition, EGFR is one of the responsive genes of $\beta$-catenin signalling. Therefore, Noggin could weaken the BMP-mediated inhibition of PI3K/Akt pathway signalling, leading in turn to enhanced $\beta$-catenin signalling. The enhanced $\beta$-catenin signalling consequently results in the upregulation of EGFR. To verify this hypothesis, the nuclear protein level of $\beta$-catenin was determined in cells in which the expression of Noggin was manipulated. An increase in nuclear $\beta$-catenin expression was observed in the AGS ${ }^{\text {NOGexp }}$ cells, while a reduced nuclear $\beta$-catenin expression was evident in the HGC27 ${ }^{\text {NOGSh }}$ cells. The addition of $\beta$-catenin inhibitor diminished the upregulation of EGFR induced by Noggin overexpression in the AGS cells, as well as the promotion of proliferation. These findings indicate that Noggin overexpression increases EGFR transcription by promoting the nuclear translocation of $\beta$-catenin. Moreover, it was found that EGFR, Akt and ERK inhibitors also diminished the Noggin-promoted nuclear translocation of $\beta$-catenin in the Noggin-overexpressing AGS cell lines, which was in line with the findings of previous studies demonstrating that the EGFR-mediated PI3K/Akt activation promotes $\beta$-catenin transactivation $(23,24)$. This suggests that a reciprocal regulatory network exists among among EGFR, BMP and $\beta$-catenin signalling, as shown in Fig. 6A. BMP plays an inhibitory role in coordinating EGFR signalling via the PTEN/PI3K/Akt pathway to limit the nuclear translocation of $\beta$-catenin, thus regulating EGFR. On the other hand, EGFR can also prevent the nuclear translocation of Smad signalling complex through the activation of ERK1/2 (14). This signalling network orchestrates a balanced and harmonious response to external stimuli. An elevated Noggin expression impairs the balance between EGFR and BMP signalling by the increasing the nuclear translocation of $\beta$-catenin, which consequently enhances the vicious circle formed by EGFR/ERK/Akt/ $\beta$-catenin in GC cells. Some studies have evaluated the efficacy and safety of anti-EGFR drugs, including monoclonal antibodies, such as cetuximab and tyrosine kinase inhibitors, such as gefitinib in GC (37-40). Phase II trials combining these agents with cytotoxics in unselected patients with GC have yielded high response rates between 41 and $65 \%$ in the first line setting $(37,38)$. However, all of the phase III trials investigating the role of anti-EGFR therapy in combination with chemotherapy in GC were negative $(39,40)$. The disappointing results of phase III clinical trials could be explained by the lack of patient selection for those likely to respond to treatment effectively. Therefore, it is crucial to further study the molecular mechanisms of GC in which EGFR is involved. This will provide a basis for the clinical screening of patients who can benefit from anti-EGFR drugs. In the present study, it was found that Noggin promotes the proliferation of GC cells mainly through the upregulation of EGFR by promoting the nuclear translocation of $\beta$-catenin. These data suggest that Noggin may be a determining factor for the prognosis and therapeutic treatment of EGFR-positive gastric tumours.

Of note, the elevated activation of ERK and Akt was also observed in the HGC27 cells in which Noggin was knocked down, although by contrast, EGFR was barely detected. The expression of EGFR was analysed at the mRNA level in different GC cell lines in the GSE36139 database, and it 
was found that EGFR expression in the HGC27 cell line was significantly lower than that of other cell lines (data not shown). The reason for this may be the failure to detect EGFR bands in the HGC27 cell line in the western blot analysis experiments. The elevated activation of ERK and Akt in the HGC27 cells in which Noggin was knocked down could be a result of the increased Smad-independent signalling of BMP following the loss of Noggin. Although some BMPs, such as BMP-10 can inhibit the proliferation of prostate cancer cells via Smad independent signalling (41), there are still many gaps here for the knowledge of differences in MAPK pathways triggered by different upstream signals, such as EGFR and BMP receptors.

There are some limitations to the present study. Firstly, the knockdown and overexpression of Noggin was established in HGC27 and AGS using the lentiviral Noggin shRNA and Noggin overexpression plasmid vectors, respectively. However, these results need to be verified in other GC cell lines. Secondly, the present study did not examine these key molecules, such as EGFR in GC specimens to verify the underlying mechanisms. These are the directions for further research in the future.

In conclusion, a higher expression of Noggin was significantly associated with the poorer survival of patients with GC. Noggin promotes proliferation of GC cells mainly through the upregulation of EGFR by promoting the nuclear translocation of $\beta$-catenin. An association between a high expression of Noggin and a shorter overall survival was evident in tumours expressing higher levels of EGFR. Further studies are required to elucidate the prognostic and therapeutic potential of this molecule in the personalized disease management for GC, particularly in EGFR-targeted therapy.

\section{Acknowledgements}

ZS is a recipient of the Chinese Scholarship from Cardiff University. The authors also wish to acknowledge the support for this collaborative research of gastric cancer from both Peking University and Cardiff University.

\section{Funding}

No funding was received.

\section{Availability of data and materials}

The datasets supporting the conclusions of the present study and relate materials are available upon request.

\section{Authors' contributions}

LY designed the experiments of the study. ZS, CZ and LY wrote the manuscript. ZS, XG, SC, CZ and MX performed the experiments. ZS, WGJ and LY performed the data analyses. JJ and XG were responsible for tissue collection and the preparation of RNA. FR performed the immunohistochemistry experiment. PG and MRP performed the histological evaluation and confirmation. ZS and PHS performed the semi-quantification of immunochemical staining. ZS, XG, CZ, FR, SC, PG, WGJ and LY made contributions to the revision and proofreading of the manuscript.

\section{Ethics approval and consent to participate}

All procedures performed in experiments involving human participants were performed in accordance with Peking University Cancer Hospital Research Ethics Committee and with the 1964 Helsinki declaration and its later amendments or comparable ethical standards. Informed consent was obtained from all individual participants included in the study.

\section{Patient consent for publication}

Not applicable.

\section{Competing interests}

The authors declare that they have no competing interests.

\section{References}

1. Todisco A: Regulation of gastric metaplasia, dysplasia, and neoplasia by bone morphogenetic protein signaling. Cell Mol Gastroenterol Hepatol 3: 339-347, 2017.

2. Nitsche H, Ramamoorthy S, Sareban M, Pausawasdi N and Todisco A: Functional role of bone morphogenetic protein-4 in isolated canine parietal cells. Am J Physiol Gastrointest Liver Physiol 293: G607-G614, 2007.

3. Maloum F, Allaire JM, Gagné-Sansfaçon J, Roy E, Belleville K, Sarret P, Morisset J, Carrier JC, Mishina Y, Kaestner KH, et al: Epithelial BMP signaling is required for proper specification of epithelial cell lineages and gastric endocrine cells. Am J Physiol Gastrointest Liver Physiol 300: G1065-G1079, 2011.

4. Wen XZ, Akiyama Y, Baylin SB and Yuasa Y: Frequent epigenetic silencing of the bone morphogenetic protein 2 gene through methylation in gastric carcinomas. Oncogene 25: 2666-2673, 2006.

5. Cancer Genome Atlas Research Network: Comprehensive molecular characterization of gastric adenocarcinoma. Nature 513: 202-209, 2014.

6. Kim SG, Park HR, Min SK, Choi JY, Koh SH, Kim JW and Lee HW: Expression of bone morphogenic protein-4 is inversely related to prevalence of lymph node metastasis in gastric adenocarcinoma. Surg Today 41: 688-692, 2011.

7. Kang MH, Oh SC, Lee HJ, Kang HN, Kim JL, Kim JS and Yoo YA: Metastatic function of BMP-2 in gastric cancer cells: The role of PI3K/AKT, MAPK, the NF- $x \mathrm{~B}$ pathway, and MMP-9 expression. Exp Cell Res 317: 1746-1762, 2011.

8. Tarragona M, Pavlovic M, Arnal-Estapé A, Urosevic J, Morales M, Guiu M, Planet E, González-Suárez E and Gomis RR: Identification of NOG as a specific breast cancer bone metastasis-supporting gene. J Biol Chem 287: 21346-21355, 2012.

9. Virk MS, Petrigliano FA, Liu NQ, Chatziioannou AF, Stout D, Kang CO, Dougall WC and Lieberman JR: Influence of simultaneous targeting of the bone morphogenetic protein pathway and RANK/RANKL axis in osteolytic prostate cancer lesion in bone. Bone 44: 160-167, 2009.

10. Laurila R, Parkkila S, Isola J, Kallioniemi A and Alarmo EL: The expression patterns of gremlin 1 and noggin in normal adult and tumor tissues. Int J Clin Exp Pathol 6: 1400-1408, 2013.

11. Szász AM, Lánczky A, Nagy Á, Förster S, Hark K, Green JE, Boussioutas A, Busuttil R, Szabó A and Győrffy B: Cross-validation of survival associated biomarkers in gastric cancer using transcriptomic data of 1,065 patients. Oncotarget 7: 49322-49333, 2016.

12. Vasaikar SV, Straub P, Wang J and Zhang B: LinkedOmics: Analyzing multi-omics data within and across 32 cancer types. Nucleic Acids Res 46 (D1): D956-D963, 2018.

13. Livak KJ and Schmittgen TD: Analysis of relative gene expression data using real-time quantitative PCR and the 2(-Delta Delta C(T)) Method. Methods 25: 402-408, 2001.

14. Guo X and Wang XF: Signaling cross-talk between TGF-beta/BMP and other pathways. Cell Res 19: 71-88, 2009.

15. da Cunha Santos G, Shepherd FA and Tsao MS: EGFR mutations and lung cancer. Annu Rev Pathol 6: 49-69, 2011.

16. Khan SA, Zeng Z, Shia J and Paty PB: EGFR gene amplification and KRAS mutation predict response to combination targeted therapy in metastatic colorectal cancer. Pathol Oncol Res 23: 673-677, 2017. 
17. Troiani T, Martinelli E, Capasso A, Morgillo F, Orditura M, De Vita $F$ and Ciardiello F: Targeting EGFR in pancreatic cancer treatment. Curr Drug Targets 13: 802-810, 2012.

18. Zhao L, He LR, Xi M, Cai MY, Shen JX, Li QQ, Liao YJ, Qian D, Feng ZZ, Zeng YX, et al: Nimotuzumab promotes radiosensitivity of EGFR-overexpression esophageal squamous cell carcinoma cells by upregulating IGFBP-3. J Transl Med 10: 249, 2012.

19. Weng X, Zhang H, Ye J, Kan M, Liu F, Wang T, Deng J, Tan Y, $\mathrm{He} \mathrm{L}$ and Liu Y: Hypermethylated Epidermal growth factor receptor (EGFR) promoter is associated with gastric cancer. Sci Rep 5: 10154, 2015.

20. Nam HJ, Ching KA, Kan J, Kim HP, Han SW, Im SA, Kim TY, Christensen JG, Oh DY and Bang YJ: Evaluation of the antitumor effects and mechanisms of PF00299804, a pan-HER inhibitor, alone or in combination with chemotherapy or targeted agents in gastric cancer. Mol Cancer Ther 11: 439-451, 2012.

21. Zhang J, He XC, Tong WG, Johnson T, Wiedemann LM, Mishina Y, Feng JQ and Li L: Bone morphogenetic protein signaling inhibits hair follicle anagen induction by restricting epithelial stem/progenitor cell activation and expansion. Stem Cells 24: 2826-2839, 2006.

22. Yang L, Meng F, Ma D, Xie W and Fang M: Bridging Decapentaplegic and wingless signaling in Drosophila wings through repression of naked cuticle by Brinker. Development 140: 413-422, 2013

23. Lu Z, Ghosh S, Wang Z and Hunter T: Downregulation of caveolin-1 function by EGF leads to the loss of E-cadherin, increased transcriptional activity of beta-catenin, and enhanced tumor cell invasion. Cancer Cell 4: 499-515, 2003.

24. Ji H, Wang J, Nika H, Hawke D, Keezer S, Ge Q, Fang B, Fang X, Fang D, Litchfield DW, et al: EGF-induced ERK activation promotes CK2-mediated disassociation of alpha-Catenin from beta-Catenin and transactivation of beta-Catenin. Mol Cell 36: 547-559, 2009.

25. Klose A, Waerzeggers Y, Monfared P, Vukicevic S, Kaijzel EL, Winkeler A, Wickenhauser C, Löwik CW and Jacobs AH: Imaging bone morphogenetic protein 7 induced cell cycle arrest in experimental gliomas. Neoplasia 13: 276-285, 2011.

26. Terashima M, Kitada K, Ochiai A, Ichikawa W, Kurahashi I, Sakuramoto S, Katai H, Sano T, Imamura H and Sasako M ACTS-GC Group: Impact of expression of human epidermal growth factor receptors EGFR and ERBB2 on survival in stage II/III gastric cancer. Clin Cancer Res 18: 5992-6000, 2012.

27. Kim MA, Lee HS, Lee HE, Jeon YK, Yang HK and Kim WH: EGFR in gastric carcinomas: Prognostic significance of protein overexpression and high gene copy number. Histopathology 52 738-746, 2008.

28. Petrini I, Lencioni M, Vasile E, Fornaro L, Belluomini L, Pasquini G, Ginocchi L, Caparello C, Musettini G, Vivaldi C, et al: EGFR and AKT1 overexpression are mutually exclusive and associated with a poor survival in resected gastric adenocarcinomas. Cancer Biomark 21: 731-741, 2018.

29. Moutinho C, Mateus AR, Milanezi F, Carneiro F, Seruca R and Suriano G: Epidermal growth factor receptor structural alterations in gastric cancer. BMC Cancer 8: 10, 2008.
30. Wang KL, Wu TT, Choi IS, Wang H, Resetkova E, Correa AM, Hofstetter WL, Swisher SG, Ajani JA, Rashid A, et al: Expression of epidermal growth factor receptor in esophageal and esophagogastric junction adenocarcinomas: Association with poor outcome. Cancer 109: 658-667, 2007.

31. Gkolfinopoulos S, Papamichael D, Papadimitriou K, Papanastasopoulos P, Vassiliou V and Kountourakis P: Advances in molecular, genetic and immune signatures of gastric cancer: Are we ready to apply them in our patients' decision making? World J Gastrointest Oncol 10: 172-183, 2018.

32. Shinohara M, Mao M, Keeley TM, El-Zaatari M, Lee HJ, Eaton KA, Samuelson LC, Merchant JL, Goldenring JR and Todisco A: Bone morphogenetic protein signaling regulates gastric epithelial cell development and proliferation in mice. Gastroenterology 139: 2050-2060, 2010.

33. Jin X, Yin J, Kim SH, Sohn YW, Beck S, Lim YC, Nam DH, Choi YJ and Kim H: EGFR-AKT-Smad signaling promotes formation of glioma stem-like cells and tumor angiogenesis by ID3-driven cytokine induction. Cancer Res 71: 7125-7134, 2011.

34. Sapkota G, Alarcón C, Spagnoli FM, Brivanlou AH and Massagué J: Balancing BMP signaling through integrated inputs into the Smad1 linker. Mol Cell 25: 441-454, 2007.

35. Scholze AR, Foo LC, Mulinyawe $S$ and Barres BA: BMP signaling in astrocytes downregulates EGFR to modulate survival and maturation. PLoS One 9: e110668, 2014.

36. Jamora C, DasGupta R, Kocieniewski P and Fuchs E: Links between signal transduction, transcription and adhesion in epithelial bud development. Nature 422: 317-322, 2003.

37. Wainberg ZA, Lin LS, DiCarlo B, Dao KM, Patel R, Park DJ, Wang HJ, Elashoff R, Ryba N and Hecht JR: Phase II trial of modified FOLFOX6 and erlotinib in patients with metastatic or advanced adenocarcinoma of the oesophagus and gastro-oesophageal junction. Br J Cancer 105: 760-765, 2011.

38. Lordick F, Luber B, Lorenzen S, Hegewisch-Becker S, Folprecht G, Wöll E, Decker T, Endlicher E, Röthling N, Schuster T, et al: Cetuximab plus oxaliplatin/leucovorin/5-fluorouracil in first-line metastatic gastric cancer: A phase II study of the Arbeitsgemeinschaft Internistische Onkologie (AIO). Br J Cancer 102: 500-505, 2010

39. Lordick F, Kang YK, Chung HC, Salman P, Oh SC, Bodoky G, Kurteva G, Volovat C, Moiseyenko VM, Gorbunova V, et al; Arbeitsgemeinschaft Internistische Onkologie and EXPAND Investigators: Capecitabine and cisplatin with or without cetuximab for patients with previously untreated advanced gastric cancer (EXPAND): A randomised, open-label phase 3 trial. Lancet Oncol 14: 490-499, 2013.

40. Waddell T, Chau I, Cunningham D, Gonzalez D, Okines AF, Okines C, Wotherspoon A, Saffery C, Middleton G, Wadsley J, et al: Epirubicin, oxaliplatin, and capecitabine with or without panitumumab for patients with previously untreated advanced oesophagogastric cancer (REAL3): A randomised, open-label phase 3 trial. Lancet Oncol 14: 481-489, 2013.

41. Ye L, Kynaston H and Jiang WG: Bone morphogenetic protein-10 suppresses the growth and aggressiveness of prostate cancer cells through a Smad independent pathway. J Urol 181: 2749-2759, 2009. 